\title{
Errata for ZOOLOGIA volumes 28(6) and 30(2)
}

Volume 28(6), page 803 , title:

Reads: Periscelidae

Should read: Periscelididae

Volume 30(2), page 135:

The correct version for Figure 1 is presented below:

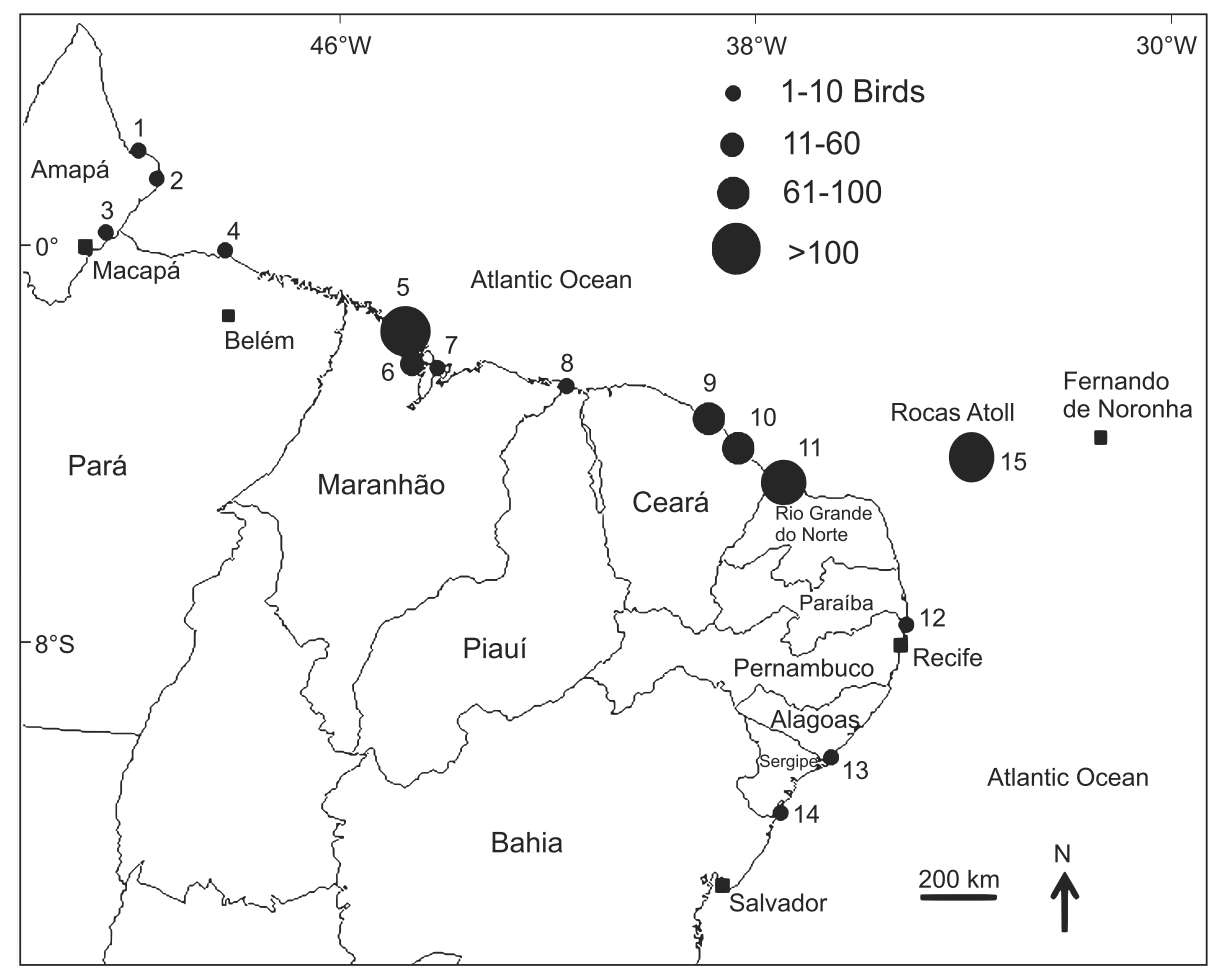

All changes are already incorporated in the online version of these articles available at http://www.scielo.br/zool 